\title{
Development and Characterization of Iron Coated Chitosan Beads (ICCB) to remove Arsenic from Groundwater
}

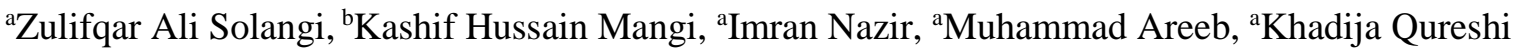 \\ $\mathrm{a}=$ Department of Chemical Engineering, Mehran University of Engineering and Technology, Jamshoro \\ $\mathrm{b}=$ Chemical Engineering Department, Quaid-e-Awam University of Science, Engineering, and Technology, \\ Nawabshah, Pakistan
}

\begin{abstract}
The current situation of Pakistan is reaching to an alarming situation in the context of polluting water bodies as well as groundwater due to various natural and anthropogenic activities, which can be foreseen for shortage and unavailability of safe and healthy drinking water for the population. The greater part of Pakistani individuals (almost $60 \%$ ) living underneath the neediness line so they don't move toward perfect and safe drinking water supplies. Arsenic is one of the hazardous metals presents in various territories of Pakistan as well as in various zones of the world. Its essence strokes individuals' wellbeing by sullying the water. This experimental adsorption study emphasizes on the arsenic removal from drinking water by utilizing cost-effective adsorbent called "Iron Coated Chitosan Beads (ICCB)". This technique is more useful and effective when contrasted with different removal methodologies to remove arsenic from groundwater. ICCB was utilized and it was discovered a compelling and productive adsorbent for the removal of arsenic from groundwater. From all clump tests, the removal level of arsenic is achieved from $79 \%$ to $98 \%$. These results demonstrated that ICCB can be utilized as a productive adsorbent material for the removal of arsenic from water.
\end{abstract}

Keywords- Arsenic removal, Iron coated chitosan beads, Groundwater treatment

Date Received 13-11-2020

Date Accepted 26-11-2020

Date Published 18-12-2020

\section{INTRODUCTION}

$\mathrm{T}$ About $2.5 \%$ of the world's assets are in freshwater [1]. Groundwater content about $30 \%$ freshwater of the biosphere's resources and $97 \%$ of it is available for human usage despite utilization purposes, underground water is comprehensively used for cultivating, mechanical, private purposes [2]. As per the United Nations (UN), almost 0.78 Billion people could not approach to safe drinking water, related with 6.6 billion individuals in 2000 by 2025, however, $66 \%$ of the total people is most likely going to live in states with water drought situation [3].

United Nations has made the struggle to solve that matter, But a huge number of individuals are still relying on perilous drinking water resources, indeed, the execution of the setobjectives of UN for the enhancing and improving the of UN Millennium project could not achieve the mission [3]. The Goal sets for Millennium Development to fraction the population proportion while not property approach to safe water by 2015 , could not be achieved [4]. The Sustainable Development Goals (SDG6) is specifically drafted and approved reforms in 2015 by UN to address the problem of water availability while setting goals for Global sustainable development (SDGs) for a plan up to 2030, where incorporation and engagement objectives for providing water to all [5]. Supportable Development objectives 6 has water committed objective 6.1 , that is, to accomplish allinclusive and impartial access to palatable and potable drinking water for all [6].
Heavy metals converted into poisonous when they are unmanaged and collect in lenient tissues. Impact of Heavy metals on Health and environment such as high exposure to Mercury causes injury to the brain and nervous system [7]. Zinc cause surely understood medical issues, for example, stomach issues, skin inconveniences, spewing, queasiness and low hemoglobin level [8]. Abundance level of zinc can harmful to the pancreas and irritate the protein digestion and cause arteriosclerosis [9]. Arsenic is one of the health hazardous metals presents in various regions of Pakistan as well as in various parts of the world. Its quality strokes individuals' wellbeing by polluting the water. Arsenic defiled drinking water cause premature deliveries and barrenness in female and it can cause skin disrupting impact, declined insurance from pollutions, cardiovascular breakdown and mental diseases [10]. Inorganic arsenic can harm DNA and malignant growth is most perilous consequence of arsenic introduction [11].

Arsenic levels more noteworthy than standard passable cutoff given by WHO $(10 \mu \mathrm{g} / \mathrm{L})$ and 50-60 million Pakistani's confronting the arsenic-polluted groundwater for drinking reason [12]. According to the Pakistan Environmental Protection Agency (PEPA) the allowable limit Surface water as drinking water is $50 \mu \mathrm{g} / \mathrm{L}$. Presently in such worse circumstance around the world, arsenic removal from drinking water is astoundingly huge. Nonetheless, in less-developed countries, present methods don't meet the reasonably on the grounds that either these systems are cost excessive [13]. In this way, a basic, modest and supportable water treatment innovation is required which satisfies water prerequisites for utilization reason [14].

This experimental study of adsorption is emphasized on the arsenic removal from drinking water by utilizing ease adsorbent called "Chitosan coated beads". This technique is more 
advantageous and prominent when contrasted with different techniques to remove arsenic from groundwater. The technique, where one part (adsorbates) is appended to outside of second constituent (adsorbent) with which they are in contact. The bonding is mainly relying on the nature and chemical characteristics of the specie involved, however, material which is adsorbed generally quoted as physisorption, chemisorption or electrostatic sorption. Mainly Bulk purification is carried out by Adsorption and widely applied on an industrial scale due to the economic aspect and ease of the process. The commercial-scale application of any adsorbent is extremely dependent on wide and significant availability of its raw material.

\section{Methodology}

\section{Materials and Equipment}

In this study, the basic materials are: Chitosan was obtained at laboratory scale from shrimp shells of commercial grade. Chitosan is nitrogenous polysaccharides are composed of glucosamine units. This polymer has structure: $(1,4)-2-$ acetamido-2-deoxy- $\beta$-D-glucan [15]. Secondly, Ferric chloride hexahydrate and finally distilled water available in the lab in the chemical engineering department, MUET, Jamshoro. List of chemicals and equipment is given in table I.

\section{Preparation of raw materials}

Shrimp shell was collected from the market and these shells were thoroughly washed with water forget shells free from all impurities such as clotted blood, rostrum, antennas, fats and dust particles then introduced these washed shells to hot air oven at $90^{\circ} \mathrm{C}$ for a quarter day. In next step homogenization of shells were takes place in a Mortar and Pestle into small-sized pieces then the particles are homogenized in the testing sieve of dia $0.634 \mathrm{~mm}$ and aperture $1.18 \mathrm{~mm}$. shells at this stage called Benefited shells. These Benefited shells were kept frozen until used. Removal of minerals was done by including $1 \mathrm{~L}$ of $1 \mathrm{M}$ of $\mathrm{HCl}$ into $100 \mathrm{~g}$ of shrimp shells. The response is completed at normal temperature under fomentation at $300 \mathrm{rpm}$ for 3 hours after the fact, the demineralized shells were filtrated, afterwards, wash with demi water till neutral $\mathrm{pH}$ accomplished. They were bleached by immersing in ethanol for $15 \mathrm{~min}$ and dry in a hot air oven at $70{ }^{\circ} \mathrm{C}$ for 2 hours.

TABLE I

List of Chemicals and Equipment [16]

\begin{tabular}{|c|c|}
\hline CHEMICALS & EQUIPMENT \\
\hline SHRIMP SHELL & $\begin{array}{l}\text { Weighing balance (Adventurer, } \\
\text { AR } 3130 \text {, OHAUS, USA). }\end{array}$ \\
\hline DISTILLED & Agitator/Stirrer \\
\hline (DISTILLED & STIRRER, MZ-800H). \\
\hline $\begin{array}{l}\text { MACHINE, MODEL NO. } \\
\text { BMS-4CE, SPAIN) }\end{array}$ & \\
\hline $\begin{array}{l}\text { FERRIC } \\
\text { HEXAHYDRATE } \\
\left(\text { FECL }_{3} \cdot 6 \mathrm{H}_{2} \mathrm{O} \text { )-CAS }\right. \\
10025-77-1\end{array}$ & $\begin{array}{l}\text { Electric oven (Wise Ven Fuzzy } \\
\text { Control System) }\end{array}$ \\
\hline $\begin{array}{l}\text { SODIUM BOROHYDRIDE } \\
\text { (NABH4)-CAS NO. 1B6940- } \\
66-2\end{array}$ & Mortar and Pestle \\
\hline $\begin{array}{l}\text { ETHANOL ABSOLUTE } \\
\left(\mathrm{C}_{2} \mathrm{H}_{5} \mathrm{OH}\right)-\mathrm{CAS} \text { NO. 67-63-0 }\end{array}$ & Ultra-freezer \\
\hline $\begin{array}{l}\text { HYDROCHLORIC ACID } \\
\text { (HCL) - CAS NO.7679-13-1 }\end{array}$ & $\begin{array}{l}\text { Mechanical shaker (WiseShaker- } \\
\text { SHR-2D) }\end{array}$ \\
\hline
\end{tabular}

\begin{tabular}{|c|c|}
\hline $\begin{array}{l}\text { SODIUM } \\
\text { (NAOH)- CAS NO.9874- } 41-2\end{array}$ & Conical flasks \\
\hline FILTER PAPERS & Hot-air oven \\
\hline $\begin{array}{l}\text { POTASSIUM ARSENATE } \\
\text { MONOBASIC }\left(\mathrm{ASH}_{2} \mathrm{KO}_{4}\right)- \\
\text { CAS NO.7784-41-0 }\end{array}$ & Testing sieve \\
\hline $\begin{array}{l}\text { STOCK } \\
\text { (100PPM,10PPM AND 1PPM) }\end{array}$ & Ball mill \\
\hline \multirow[t]{3}{*}{$\begin{array}{l}\text { NITRIC ACID }\left(\mathrm{HNO}_{3}\right)-\mathrm{CAS} \\
\text { NO.7889-67-7 }\end{array}$} & $\begin{array}{l}\text { Atomic Absorption } \\
\text { (AAnectroscopy } \\
\text { USA) }\end{array}$ \\
\hline & $\begin{array}{l}\text { Scanning electron microscope } \\
\text { (SEM) }\end{array}$ \\
\hline & $\begin{array}{l}\text { Fourier-transform } \\
\text { spectroscopy (FTIR) }\end{array}$ \\
\hline
\end{tabular}

Deproteinization of Chitin was finished by the introduction of $1 \mathrm{M}$ caustic to shells at solid to fluid proportion of $1 \mathrm{~g}: 10 \mathrm{~mL}$ Reaction was done under agitated temperature $80{ }^{\circ} \mathrm{C}$ for 3 hours. Solutes were filtrated and afterwards wash with demi water till its $\mathrm{pH}$ became neutral. At that point, for further bleaching, it was immersed in ethanol for $10 \mathrm{~min}$, and the subsequent chitin was dried in an oven at $70{ }^{\circ} \mathrm{C}$. Deacetylation of chitin was accomplished by responding chitin with $12.5 \mathrm{M}$ caustic at a solid to fluid proportion of $1 \mathrm{~g}: 15 \mathrm{ml}$. The blend was chilled off at $-83{ }^{\circ} \mathrm{C}$ in an ultra-cooler and kept solidified for $24 \mathrm{~h}$. From that point onward, the blend temperature was raised to $115^{\circ} \mathrm{C}$, and the response continued with tumult at $250 \mathrm{rpm}$ for 5 then it was filtrated and washed with demi water until $\mathrm{pH}$ became neutral and dried in an oven at $70{ }^{\circ} \mathrm{C}$. Coating of beads is accomplished by preparing the solution $0.54 \mathrm{gm}$ of ferric chloride hexahydrate with chemical formula $\mathrm{FeCl}_{3} \cdot 6 \mathrm{H}_{2} \mathrm{O}$ (CAS No. 10025-77-1) and dissolved it in ethanol/water mixture in $4 / 1$ volume/volume ration, such that $24 \mathrm{ml}$ of ethanol, $6 \mathrm{ml}$ of distilled water was added and stirred well. For extreme accessibility of the number of tests to be treated for arsenic removal from drinking water, ferric chloride hexahydrate arrangement was set up in an enormous sum by taking 5.406 grams of $\mathrm{FeCl} 3.6 \mathrm{H} 2 \mathrm{O}$ dissolving in $120 \mathrm{ml}$ of absolute ethanol and $30 \mathrm{ml}$ of distilled water in a $1000 \mathrm{ml}$ glass cylinder sets and were blended well mechanically. Chitosan was poured into ferric chloride hexahydrate solution in ratio $10 \mathrm{gm}$ solid in 100 $\mathrm{ml}$ of solution and put this into magnetic stirrer at $300 \mathrm{rpm}$ for 2 hours at room temperature afterwards filter that solution to recover filtrate and finally put filtrate into the oven at $90{ }^{\circ} \mathrm{C}$ for 3 Hours now coated beads of chitosan are ready for use.

\section{Preparation of samples}

Different samples were prepared as a batch process by taking adsorbent in a flask containing the arsenic solution of concentration 50ppb, cover the flask and placed it on the wise shaker and shaken at $200 \mathrm{rpm}$ at room temperature $\left(25 \pm 1^{\circ} \mathrm{C}\right)$ for periods up to $120 \mathrm{~min}$. The current study includes optimization of many operating parameters such as dosage of adsorbent, $\mathrm{pH}$, mixing time of the experiment, and mixing speed of agitator for batch experiments. The dosage range of $(0.25$ to $1.0 \mathrm{~g})$, mixing speed range $(30-120 \mathrm{rpm})$, duration of the experiment $(0.5$ to $2.0 \mathrm{~h})$ at a controlled laboratory temperature of $25 \pm 1^{\circ} \mathrm{C}$, and $\mathrm{pH}$ range of $2-10$ of the arsenic solution was adjusted by adding $0.1 \mathrm{M} \mathrm{NaOH}$ were considered 
for the investigation of optimum operating conditions where maximum removal efficiency can be achieved.

TABLE II

List of Samples

\section{Sample \# Batch study List of samples}

\begin{tabular}{l|ll}
01 & $\mathrm{pH}$ & 02 \\
02 & & 07 \\
03 & & 10 \\
04 & Adsorbent dose & 0.25 \\
05 & $($ gm $)$ & 0.5 \\
06 & & 0.75 \\
07 & & 1 \\
08 & Shaking Speed & 50 \\
09 & (rpm) & 100 \\
10 & & 150 \\
11 & & 200 \\
12 & Contact Time & 30 \\
13 & (min) & 60 \\
14 & & 90 \\
15 & & 120
\end{tabular}

After completion of every batch experiment, the solution was left for gravitational sedimentation and filtered through traditional filter papers, afterwards the residual arsenic test was carried for each sample on atomic absorption spectrometer.

\section{Adsorbent Characterization}

Analytical equipments including SEM- ScanningElectron-Microscopy, and FTIR-Fourier-transform Infrared were used to conduct an intensive Characterization of adsorbent including analyze the structure of adsorbent during different stages and its behavior at different wave number. The developed adsorbent's morphological features and surface characteristics were analyzed for each batch after applying arsenic contaminated water and same was carried out before starting of experiment. All the tests were obtained with an accelerated voltage $5 \mathrm{kV}$ and $1,000 \mathrm{x}$ magnification. The functional groups which can be effective in for holding or taking-up the surface of iron coated beads of chitosan ICCB were analyzed through FTIR spectroscopy with a range of wavelength i.e. $4000-5000 \mathrm{~cm}^{-1}$.

\section{RESULTS AND DISCUSSION}

\section{Adsorbent Characterization}

The morphology of the chitosan was investigated by (SEM), Every stage of chitosan development of was examined intensively including washing of shrimp shell, demineralization stage, depotentiation and deacetylation of shrimp shells. Photograph 1 shows that shrimp shells display a diverse behaviour characterized as a smaller structure with exact round formed white spots. After demineralization, it displays huge changes in material surface, white spots are currently substituted by bent gaps coming about because of the evacuation of $\mathrm{CaCO}_{3}$ by the corrosive treatment. SEM micrographs of deacetylated test CHI-4 additionally display that chitosan gets sinewy structure. It merits referencing that most of the examples of chitosan delivered by procedures utilized to acquire chitosan displayed comparative morphological conduct. Photograph 2 shows that covered beads have translucent cleaned surface all the holes of chitosan were filled by covering of iron it implies dabs are great and prepared for use. After adsorption structure of beads were the upset surface of beads become delicate, which means that a portion of beads was adsorbed and participated in the removing of Arsenic through adsorption.

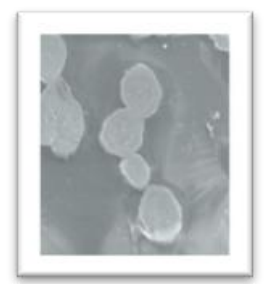

Shrimp shell

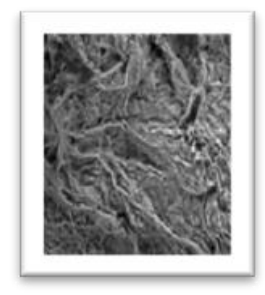

Demineralized shell

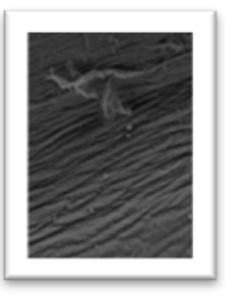

Chitosan
Photograph 1: SEM of Shrimp shell, shells after demineralization, shells after deproteinization

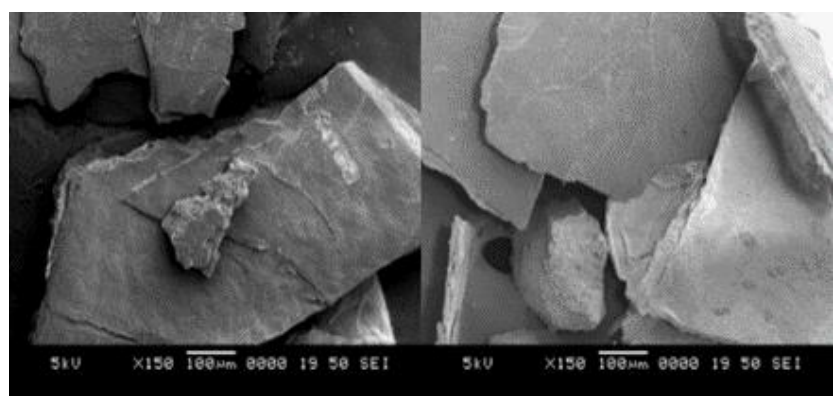

Photograph 2: SEM of Chitosan coated beads before and after adsorption.

Figure 1, 2 and 3 show the FT-IR spectrum of the chitosancoated beads before and after use respectively. In Figure 1, the FT-IR spectra of chitosan show the characteristic absorption bands at $3450 \mathrm{~cm}-1 \mathrm{O}-\mathrm{H}$ extending, at $1870-2880 \mathrm{~cm}-1 \mathrm{CH}$ stretching, at $1655 \mathrm{~cm}-1$ Amide I bending, at $1580 \mathrm{~cm}-1 \mathrm{NH}_{2}$ bending, and at $1320 \mathrm{~cm}-1$ Amide III bending takes place. The absorption bands at $1160 \mathrm{~cm}-1$ represent anti-symmetric stretching of the $\mathrm{C}-\mathrm{O}-\mathrm{C}$ bridge.

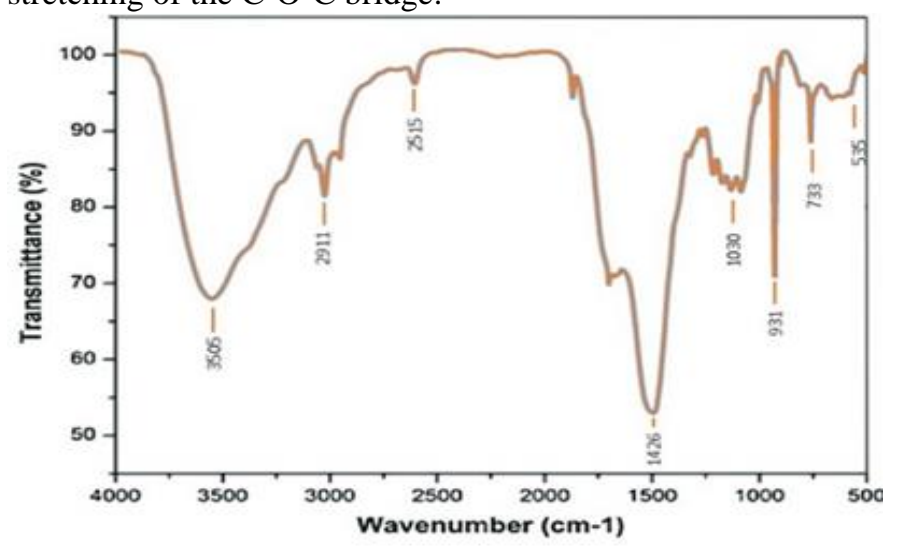

Fig 1. FTIR spectra of prepared chitosan sample 


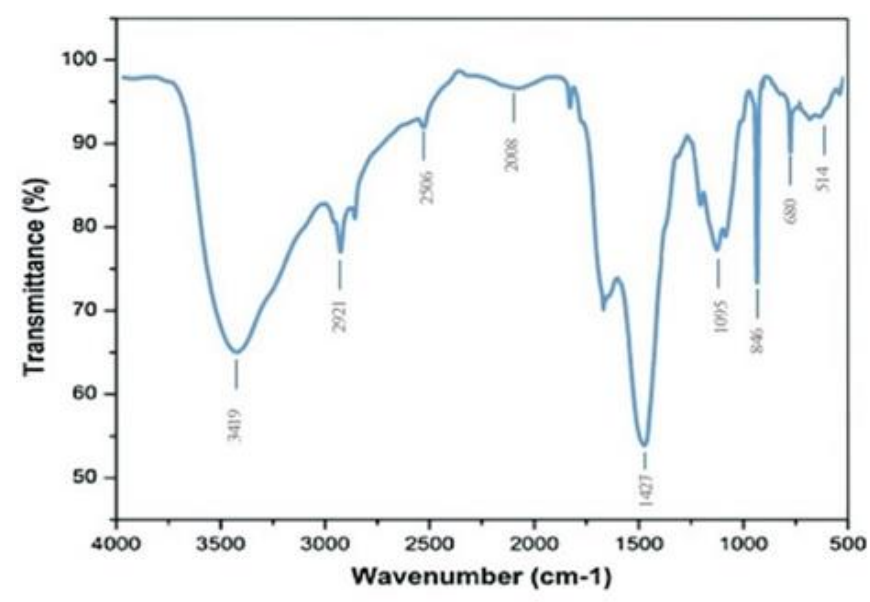

Fig 2. FTIR spectra of chitosan-coated beads before adsorption Figure 2 shows the FT-IR spectra of chitosan-coated beads before adsorption at $3505 \mathrm{~cm}-1$ (O-H stretching) of Alcohol, $2911 \mathrm{~cm} \mathrm{-1} \mathrm{(C-H} \mathrm{stretching)} \mathrm{of} \mathrm{Alkane,} \mathrm{At} 2515$ (S-H stretching) of thiol, At 1426 (O-H bending) of carboxylic acid, At $1030 \mathrm{~cm}-1$ (CO-O-CO stretching) of anhydride, At $931 \mathrm{~cm}-$ $1(\mathrm{C}=\mathrm{C}$ bending $)$ of Alkene disubstituted trans and on $733 \mathrm{~cm}-$ $1(\mathrm{C}=\mathrm{C}$ bending $)$ of Alkene disubstituted cis.

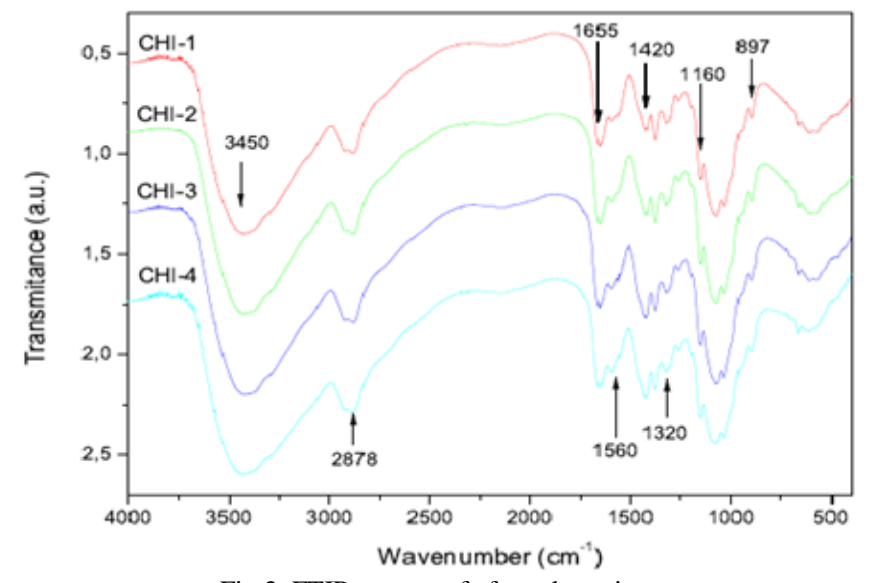

Fig 3. FTIR spectra of after adsorption

Figure 3 shows the FT-IR spectra of chitosan-coated beads after adsorption at $3419 \mathrm{~cm}-1$ (O-H stretching) of Alcohol, at 2921 cm-1 (C-H stretching) of Alkane, at $2506 \mathrm{~cm}-1$ (S-H stretching ) of thiol, at $2008(\mathrm{C}=\mathrm{C}=\mathrm{C})$ medium stretching of Alkenes, at $1421 \mathrm{~cm}-1$ (O-H bending) of carboxylic acid, At $1095 \mathrm{~cm}-1$ (C$\mathrm{O}$ stretching) of secondary alcohols, At $846 \mathrm{~cm}-1$ (C-Cl stretching) of halo compounds, at $680 \mathrm{~cm}-1$ ( $\mathrm{C}=\mathrm{C}$ bending) of Alkene disubstituted cis takes place.

\section{Batch Adsorption Studies}

\section{Effect of Adsorbent Dosage}

The impact of adsorbent measurements is a significant parameter in choosing the economy of material. The economy of the material was examined on four distinct measurements from 0.25 to $1 \mathrm{~g} / \mathrm{l}$. while keeping different parameters steady for example $47.9 \mu \mathrm{g} / \mathrm{L}$ at $\mathrm{pH} 7$ unsettled for 120 minutes for finding the arsenic expulsion productivity and evacuation limit of Chitosan coated beads. The per cent evacuation of arsenic was expiring by expanding the adsorbent portion after $0.5 \mathrm{mg} / \mathrm{l}$ as appeared in Figure 4. This could be credited to the immersion of the adsorbent surface by adsorbate particles.

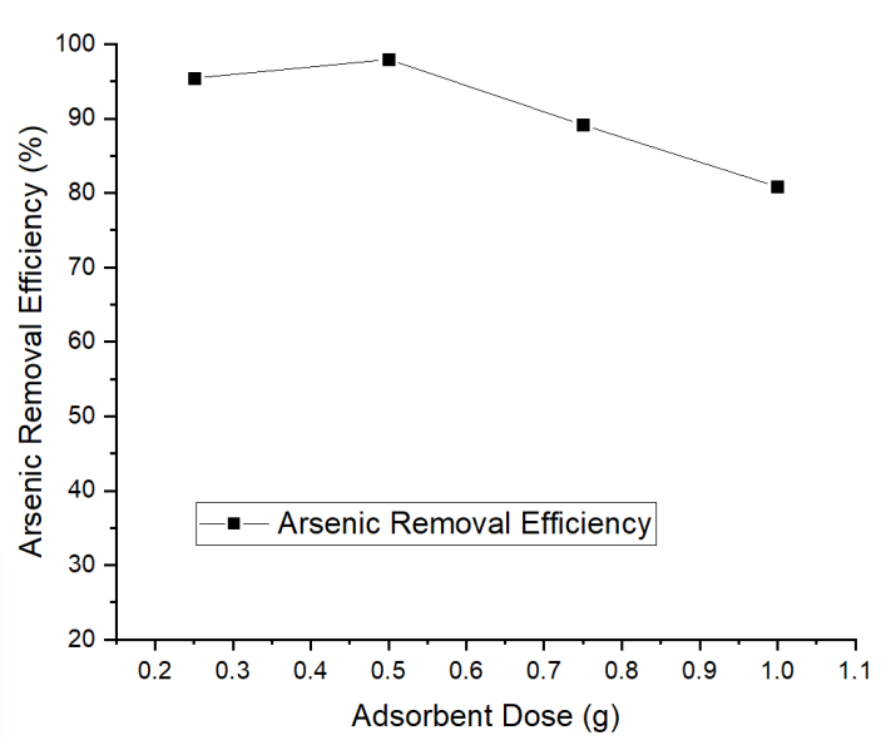

Fig 4. Effect of adsorbent dose on Arsenic removal efficiency

\section{Effect of $\mathbf{p H}$}

The $\mathrm{pH}$ of the solution is a critical observing parameter in driving an adsorption procedure. In the current investigation, the impact of $\mathrm{pH}$ on expulsion level of arsenic was tested. To research the $\mathrm{pH}$ esteem on the presentation of arsenic expulsion productivity and take-up limit of chitosan covered dots, tests were set up at different $\mathrm{pH}$ esteems for example 2, 7 and 10 with an underlying convergence of $47.9 \mu \mathrm{g} / \mathrm{L}$, adsorbent portion of $0.5 \mathrm{~g} / \mathrm{l}$, adsorption time of 120 minutes at the room temperature of $25^{\circ} \mathrm{C}$ as appeared in figure 5 .

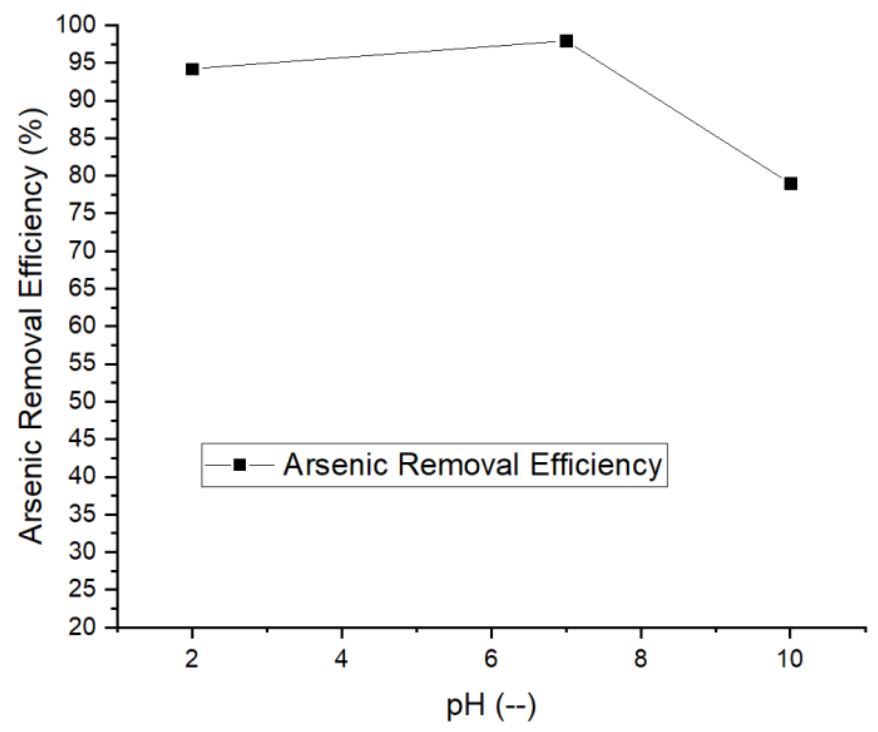

Fig 5. Effect of $\mathrm{pH}$ on Arsenic Removal efficiency

\section{Effect of shaking speed}

Shaking speed is also a critical observing parameter in the adsorption procedure. In the current investigation, the impact of shaking speed on expulsion level of arsenic was tested. The presentation of arsenic expulsion productivity and take-up limit of chitosan covered beads, tests were set up at different speed esteems for example $50 \mathrm{rpm}, 100 \mathrm{rpm}, 150 \mathrm{rpm}$ and $200 \mathrm{rpm}$ with an underlying convergence of $47.9 \mu \mathrm{g} / \mathrm{L}$, adsorbent portion of $0.5 \mathrm{~g} / \mathrm{l}$, adsorption time of 120 minutes at the room temperature of $25^{\circ} \mathrm{C}$ as appeared in figure 6 . 


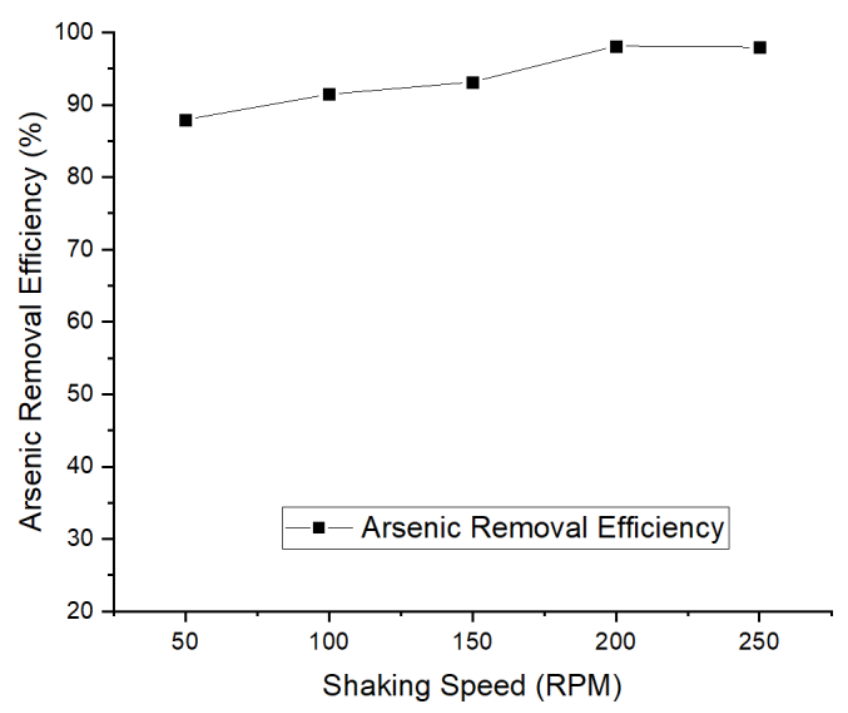

Fig. 6. Effect of shaking speed on Arsenic removal efficiency

\section{Effect of contact time}

Contact time is also a critical observing parameter in the adsorption procedure. In the current investigation, the impact of shaking time on expulsion level of arsenic was tested.

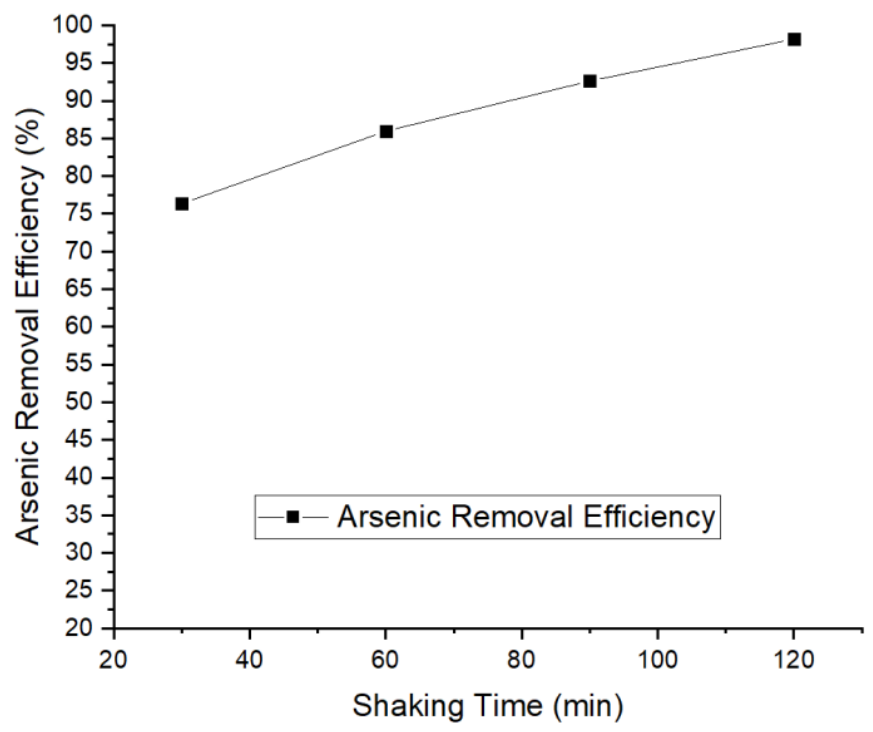

Fig 7. Effect of shaking time on Arsenic removal efficiency

The presentation of arsenic expulsion productivity and take-up limit of chitosan covered beads, tests were set up at different time esteems for example $30 \mathrm{~min}, 60 \mathrm{~min}, 90 \mathrm{~min}$ and $120 \mathrm{~min}$ with an underlying convergence of $47.9 \mu \mathrm{g} / \mathrm{L}$, adsorbent portion of $0.5 \mathrm{~g} / \mathrm{l}$, adsorption speed of $200 \mathrm{rpm}$ at the room temperature of $25^{\circ} \mathrm{C}$ as appeared in figure 7.

\section{Adsorption Isotherms}

The adsorption capacity of developed adsorbent was evaluated as the ratio of Arsenic adsorbed mass by mass of the Iron coated beads of chitosan. Nature of adsorption can be explained by relating the adsorbent remained in the solution after reaching the equilibrium concentration by employing different isotherms. The most frequent isotherms of adsorption including Langmuir and Freundlich are demonstrated in Figure 8 and 9. Figure 8 demonstrated a straight line for (1/qe) vs. $(1 / \mathrm{Ce})$ with an empirical constant achieved through kinetic data as shown in both graphs. The equilibrium concentration is denoted by $C e(m g / L)$, however $q e(\mathrm{mg} / \mathrm{g})$ is showing the adsorbent amount at equilibrium condition, the constant of adsorption capacity is ' $a$ ',

\begin{tabular}{|c|c|c|c|}
\hline \multicolumn{4}{|c|}{$\begin{array}{c}\text { TABLE III } \\
\text { Isotherm Constant }\end{array}$} \\
\hline $\begin{array}{l}\text { Isotherm } \\
\text { Model }\end{array}$ & \multicolumn{2}{|l|}{ Isotherm Constants } & $\mathbf{R 2}$ \\
\hline \multirow{2}{*}{$\begin{array}{l}\text { Langmuir } \\
\text { Isotherm }\end{array}$} & $\begin{array}{l}\text { adsorption capacity } \\
q_{m}(\mathrm{mg} / \mathrm{g})\end{array}$ & $\begin{array}{l}\text { rate of adsorption } \\
b(\mathrm{lit} / \mathrm{mg})\end{array}$ & \multirow[t]{2}{*}{0.994} \\
\hline & 0.276933 & 18.41622 & \\
\hline \multirow{2}{*}{$\begin{array}{l}\text { Freundlich } \\
\text { Isotherm }\end{array}$} & $\begin{array}{l}\text { adsorption capacity } \\
\mathrm{kf}(\mathrm{mg} / \mathrm{g})\end{array}$ & $\begin{array}{l}\text { Adsorption intensity } \\
\mathrm{n}\end{array}$ & \multirow{2}{*}{0.999} \\
\hline & 1.54 & 1.218 & \\
\hline
\end{tabular}

and energy adsorption constant is shown by ' $b$ '. Both isotherm models i.e. Freundlich and Langmuir showed a great satisfaction while applied for the fitting of " $R$ " " as presented in figure 8 , and 9 with a value of (0.994 and 0.999) respectively. Furthermore, a detailed discussion on the constants is briefly demonstrated in Table III.

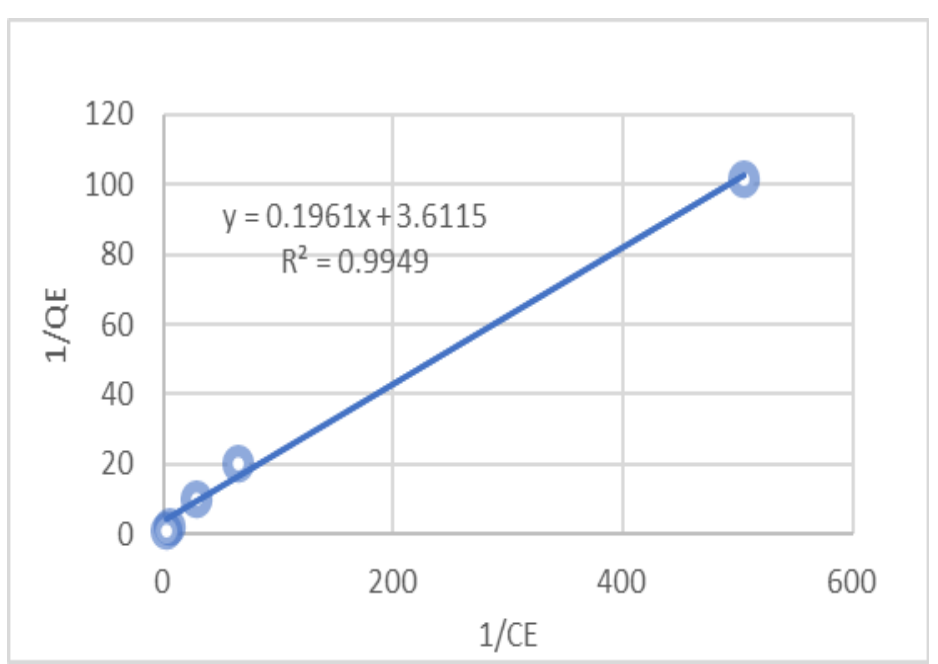

Fig. 8. Langmuir Isotherm for Arsenic-ICCB

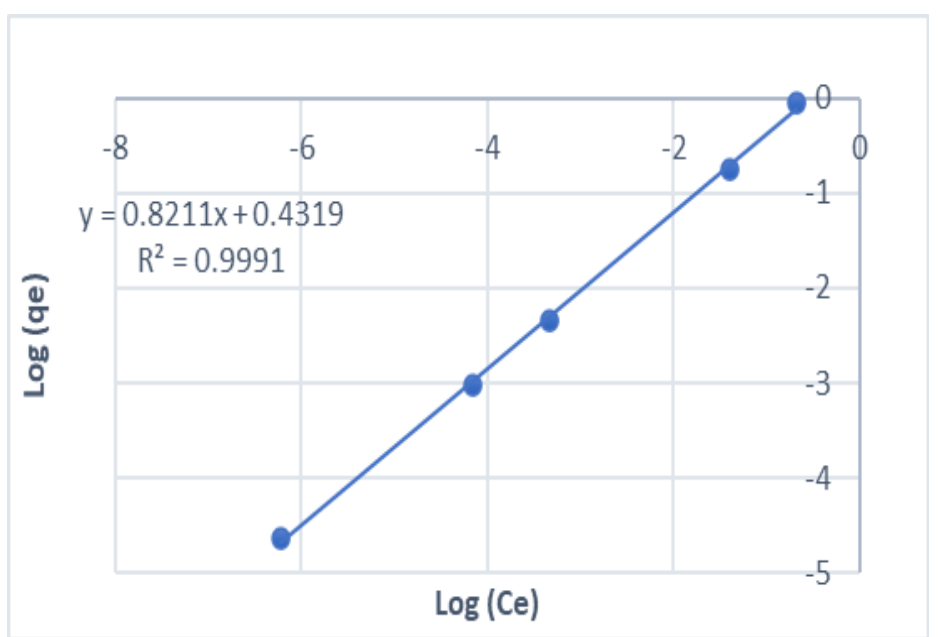

Fig. 9. Freundlich Isotherm for Arsenic-ICCB 


\section{CONCLUSION}

The current study was intensively focused to develop Iron Coated Beads of Chitosan (ICCB) and it was discovered that the developed ICCB can be a powerful and productive adsorbent for the removal of arsenic from groundwater. It was revealed by a detailed experimental study that arsenic removal efficiency of developed ICCB can be reached up to $98 \%$ at an adsorbent dosage of $0.5 \mathrm{~g} / 50 \mathrm{ml}$ and on neutral $\mathrm{pH}$ range, however, mixing speed was 200 RPM and mixing was continued up to 2 hours. Arsenic removal from the water was determined using Atomic Absorption spectroscopy. This study indicated that ICCB is widely available at low cost and can be used as an efficient adsorbent material for the removal of arsenic from water. Isotherm study represents only $0.277 \mathrm{mg}$ of ICCB required for the removal of $1 \mathrm{gm}$ of Arsenic, so it is best and cost-effective adsorbent to deal arsenic issue of water.

\section{REFERENCES}

[1] L. Da Sacco and A. Masotti, "Chitin and chitosan as multipurpose natural polymers for groundwater arsenic removal and As2O3 delivery in tumor therapy," Marine drugs, vol. 8, pp. 1518-1525, 2010

[2] D. D. Gang, B. Deng, and L. Lin, "As (III) removal using an iron-impregnated chitosan sorbent," Journal of Hazardous Materials, vol. 182, pp. 156-161, 2010.

[3] Gupta, V. S. Chauhan, and N. Sankararamakrishnan, "Preparation and evaluation of iron-chitosan composites for removal of As (III) and As (V) from arsenic contaminated real life groundwater," Water research, vol. 43, pp. 3862-3870, 2009.

[4] M. T. Sikder, Y. Mihara, M. S. Islam, T. Saito, S. Tanaka, and M. Kurasaki, "Preparation and characterization of chitosan-caboxymethyl- $\beta$-cyclodextrin entrapped nanozero-valent iron composite for $\mathrm{Cu}$ (II) and $\mathrm{Cr}$ (IV) removal from wastewater," Chemical Engineering Journal, vol. 236, pp. 378-387, 2014

[5] C.-C. Chen and Y.-C. Chung, "Arsenic removal using a biopolymer chitosan sorbent," Journal of Environmental Science and Health, Part A, vol. 41, pp. 645-658, 2006.

[6] M. Saifuddin and P. Kumaran, "Removal of heavy metal from industrial wastewater using chitosan coated oil palm shell charcoal," Electronic journal of Biotechnology, vol. 8, pp. 43-53, 2005.

[7] S. M. Miller and J. B. Zimmerman, "Novel, bio-based, photoactive arsenic sorbent: TiO2-impregnated chitosan bead," Water research, vol. 44, pp. 5722-5729, 2010.

[8] J. He, F. Bardelli, A. Gehin, E. Silvester, and L. Charlet, "Novel chitosan goethite bionanocomposite beads for arsenic remediation," Water research, vol. 101, pp. 1-9, 2016.

[9] X. Guo and F. Chen, "Removal of arsenic by bead cellulose loaded with iron oxyhydroxide from groundwater," Environmental science \& technology, vol. 39, pp. 6808-6818, 2005.

[10] S. Saha and P. Sarkar, "Arsenic remediation from drinking water by synthesized nano-alumina dispersed in chitosangrafted polyacrylamide," Journal of hazardous materials, vol. 227, pp. 68-78, 2012.
[11] L.-L. Min, L.-B. Zhong, Y.-M. Zheng, Q. Liu, Z.-H. Yuan, and L.-M. Yang, "Functionalized chitosan electrospun nanofiber for effective removal of trace arsenate from water," Scientific reports, vol. 6, p. 32480, 2016.

[12] D. Chauhan, J. Dwivedi, and N. Sankararamakrishnan, "Novel chitosan/PVA/zerovalent iron biopolymeric nanofibers with enhanced arsenic removal applications," Environmental Science and Pollution Research, vol. 21, pp. 9430-9442, 2014.

[13] L. Dambies, T. Vincent, and E. Guibal, "Treatment of arsenic-containing solutions using chitosan derivatives: uptake mechanism and sorption performances," Water Research, vol. 36, pp. 3699-3710, 2002.

[14] S. M. Miller, M. L. Spaulding, and J. B. Zimmerman, "Optimization of capacity and kinetics for a novel biobased arsenic sorbent, TiO2-impregnated chitosan bead," Water research, vol. 45, pp. 5745-5754, 2011.

[15] J. Wang, W. Xu, L. Chen, X. Huang, and J. Liu, "Preparation and evaluation of magnetic nanoparticles impregnated chitosan beads for arsenic removal from water," Chemical Engineering Journal, vol. 251, pp. 25 34, 2014.

[16] L.-L. Min, Z.-H. Yuan, L.-B. Zhong, Q. Liu, R.-X. Wu, and Y.-M. Zheng, "Preparation of chitosan based electrospun nanofiber membrane and its adsorptive removal of arsenate from aqueous solution," Chemical Engineering Journal, vol. 267, pp. 132-141, 2015.

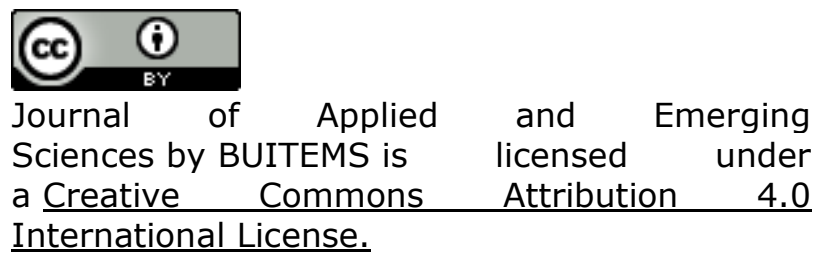

